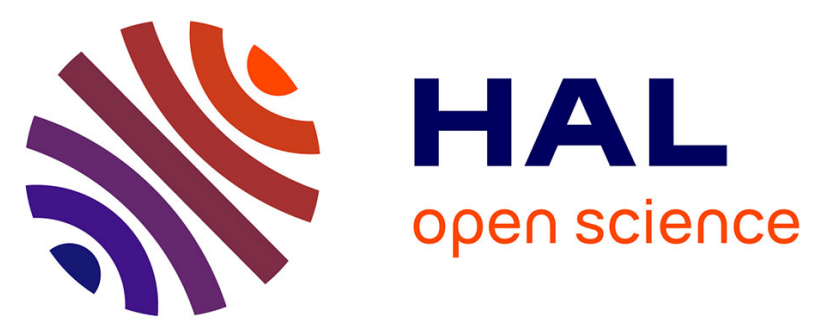

\title{
Lymphatic Transport and Lymph Node Location of Microspheres Subcutaneously Injected in the Vicinity of Tumors in a Rabbit Model of Breast Cancer
}

Florentina Pascale, Laurent Bédouet, Afchine Fazel, Julien J. Namur, Saïda Homayra Ghegediban, Isabelle Schwartz-Cornil, Michel M. Wassef, Laurence Moine, Alexandre Laurent

\section{To cite this version:}

Florentina Pascale, Laurent Bédouet, Afchine Fazel, Julien J. Namur, Saïda Homayra Ghegediban, et al.. Lymphatic Transport and Lymph Node Location of Microspheres Subcutaneously Injected in the Vicinity of Tumors in a Rabbit Model of Breast Cancer. Pharmaceutical Research, 2018, 35 (10), 10.1007/s11095-018-2474-6 . hal-02331713

\section{HAL Id: hal-02331713 \\ https://hal.science/hal-02331713}

Submitted on 24 Oct 2019

HAL is a multi-disciplinary open access archive for the deposit and dissemination of scientific research documents, whether they are published or not. The documents may come from teaching and research institutions in France or abroad, or from public or private research centers.
L'archive ouverte pluridisciplinaire HAL, est destinée au dépôt et à la diffusion de documents scientifiques de niveau recherche, publiés ou non, émanant des établissements d'enseignement et de recherche français ou étrangers, des laboratoires publics ou privés. 
Lymphatic transport and lymph node location of microspheres subcutaneously injected in the vicinity of tumors in a rabbit model of breast cancer

Florentina Pascale ${ }^{1}$, Laurent Bédouet ${ }^{2}$, Afchine Fazel $^{3}$, Julien Namur ${ }^{1}$, Saida Homayra Ghegediban ${ }^{1}$, Isabelle Schwartz Cornil ${ }^{4}$, Michel Wassef ${ }^{3}$, Laurence Moine ${ }^{6}$ and Alexandre Laurent ${ }^{3,5,7}$

From:

1. ArchimMed, 12, rue Charles de Gaulle, 78350, Jouy en Josas, France

2. Occlugel, 12, rue Charles de Gaulle, Jouy en Josas, 78350, France

3. Hôpital Lariboisière, 2, Rue Ambroise Paré, 75010, Paris, France

4. Laboratoire de Virologie et Immunologie Moleculaires, Institut National de la Recherche Agronomique, Domaine de Vilvert, Jouy en Josas, France

5. Université Paris Diderot-Paris 7, 75205, Paris CEDEX 13

6. Institut Galien Paris Sud, CNRS, Université Paris-Saclay, 5, rue Jean-Baptiste Clément, 92296 Châtenay-Malabry CEDEX, France

7. Cr2i, INRA, Domaine de Vilvert - 78352 Jouy en Josas - France

Running head: Targeting the sentinel lymphnodes by microspheres

\section{Corresponding Author and reprint request:}

Florentina PASCALE, MVD, PhD

Archimmed SARL,

12, rue Charles de Gaulle, 78350, Jouy en Josas, France

Phone : 33683913439

Fax : 33139200710

E mail : florentina.pascale@ archimmed.com 


\begin{abstract}
:
Purpose: To assess the lymphatic transport of microparticles of $100 \mathrm{~nm}, 1 \mu \mathrm{m}$ and $10 \mu \mathrm{m}$ subcutaneously injected into the breast area of healthy and tumor-bearing rabbits, and to analyze their location in lymph node (LN) in relation to malignant cells.
\end{abstract}

Methods: Female rabbits ( $n=9)$ bearing a VX2 tumor in one thoracic mammary gland were subcutaneously injected at D15 with polystyrene fluorescent particles around the nipple, on the tumor and on the healthy sides. The tumor and the LN measured by ultrasound at D9, D15 and D20 were explanted at D20. The LN metastases were evaluated by cytokeratin staining. LN uptake of the particles was measured by quantifying the green fluorescence surface in hot spot regions of healthy and pathologic LN.

Results: All animals developed mammary tumors. Metastases were found in $39 \%$ of LN from the tumor side. LN invasion was significantly lower for the $10 \mu \mathrm{m}$ group versus the $100 \mathrm{~nm}$ group ( $p<0.0348)$. The fully invaded area of metastatic LN contained significantly less $100 \mathrm{~nm}$ and $1 \mu \mathrm{m}$ particles compared to the low and non-invaded regions and to the healthy LN. In the invaded LN, the $1 \mu \mathrm{m}$ MS occupied more surface than the $100 \mathrm{~nm}$ particles.

Conclusions: $1 \mu \mathrm{m}$ MS arrived numerously into the areas low-invaded and non-invaded by the tumoral cells of the pathologic LN, but they were very rare in the fully invaded regions. Compared to the $100 \mathrm{~nm}$ nanospheres, the $1 \mu \mathrm{m}$ were better retained (20 times) into the sentinel $\mathrm{LN}$, showing the advantage of micrometric particles for lymph-targeted chemotherapy when injected before complete invasion by metastases.

Keywords: Chemotherapy, Lymph node, Lymphatic transport, Metastases, Microspheres

\title{
Abreviations:
}

LN: lymphnode

SLN: sentinel lymph node

DDS: drug delivery system

NP: nanoparticles

PLGA: poly(lactic-co-glycolic acid)

MS: microspheres 
PBS: phosphate buffered saline

$\mathrm{mAb}:$ monoclonal antibody

MW: Mann-Whitney U test

KW: Kruskal Wallis test

\section{Introduction}

Most human cancers like breast, digestive tract, lung and prostate cancer, metastasize via the lymphatic way (1). Tumors facilitate distant metastases and tumor growth by inducing lymphangiogenesis and vessel expansion in the lymph node (LN) draining them $(2,3)$. The LNs that drain solid tumors are a primary site of metastasis and are called sentinel lymph nodes (SLN). LN resident metastases have the potential to act as a reservoir for cancer cells, resulting in spreading beyond the initial metastatic site and advancement of the malignancy.

In breast cancer, the current treatments for LN metastases involve surgical removal of the SLN associated with radiation and chemotherapy. These methods are invasive and not always successful since some metastatic LNs that don't have an axillary location are difficult to access (4-6). Conventional adjuvant and neoadjuvant chemotherapy by intravenous infusion of nanoparticulate antineoplastic drugs Doxil ${ }^{\circledR}$ and Abraxane ${ }^{\circledR}$ could be efficient for the treatment of dispersed lymphatic metastases. However, they do not provide a great concentration of drug in the SLN, thus repeated administration are necessary (5) with the risk of causing systemic toxicity.

Lymph-targeted chemotherapy could enhance delivery of chemotherapeutic drugs to the SLN or to lymphatic-resident metastases, and it reduces systemic exposure. Interstitial administration (subcutaneous, intramuscular, intradermic) of the drugs near the tumor site or direct intra-tumor injection allow to concentrate the drug into the local LN draining the site of injection (5). The local sustained delivery of drugs in SLN is interesting since a prolonged exposure of tumor cells to chemotherapy over multiple cell cycles has shown to be more cytotoxic than bolus delivery for most drugs that target pathways involved in cell replication (7). 
The ideal drug delivery system (DDS) for lymph therapy of SLN metastases should have a good lymphatic transport, high LN uptake, and long residence time allowing a local prolonged drug release in a tumoricidal concentration.

In preclinical and clinical studies it was demonstrated that DDS under the form of nanoparticles reach the LN freely or transported by inflammatory cells $(8,9)$, but do not penetrate into the metastatic area $(10,11)$. Nano-carriers have a good lymphatic transport but a poor LN uptake (12-14), so the drugs they carry can be found in circulation and other organs $(15,16)$. To counter this effect studies were conducted to modify the surface of the nanoparticles (NP) in order to target cancer cells specifically [12] and to enhance the LN uptake $(6,17)$. In clinical $(18,19)$ and preclinical trials $(16,20,21)$ for the treatment of LN metastases it was stated that nanocarriers have a limited loading capacity for drug delivery and a short period of drug release, therefore, repeated sessions of treatment are necessary to achieve an anti- tumor effect.

Unlike nanocarriers, calibrated microspheres could be better candidates for lymphotherapy since their LN uptake and remanence are increased when injected via the submucosal $(22,23)$ or subcutaneous route (24) in non-pathologic animal models. When they are loaded with anti-cancer drugs, microparticles provide a drug release and antitumor efficacy superior to nanoparticles, as observed in vitro and in vivo. For instance, in vitro paclitaxel delivery from $1 \mu \mathrm{m}$ microspheres was three times more cytotoxic to $4 \mathrm{~T} 1$ cells compared to the drug delivered from nanospheres (25). When PLGA microparticles with different sizes (between $1-40 \mu \mathrm{m}$ ) were injected in intra-tumor regions or near the tumors, the antitumor efficacy was enhanced (26) and a high drug concentration in the metastatic LN was obtained (27-29). As a result the local metastases are reduced, as well as the systemic concentration of the drug (29).

The uptake mechanism and the distribution of the large particles through the metastatic nodal tissue of the SLN remain unclear. The lymphatic drainage of LN is modified during the tumor growth, the growth of metastatic tumor cells in regional LN may cause blockage of normal lymph flow and the destruction of the internal structure of the lymphatic capillaries (30). Moreover, LNs invaded by malignant cells may contain less macrophages, which could account for the decrease of particle uptake $(1,12,31)$. On the other hand it was demonstrated that tumors induce lymphangiogenesis and vessel 
expansion in their draining $\mathrm{LN}$ thus facilitating the distant metastases and tumor dissemination $(2,3)$. That suggests that the lymphatic transport of the particles loaded with chemotherapeutic drugs might be facilitated in the same way as the tumor cells transport. Many studies on lymph therapy with microparticles provide information about the concentration of drugs in SLN and their effects on LN metastases $(15,17,21,29)$. To the best of our knowledge, information about the location of micrometric DDS in relation to metastatic cells in the SLN is still lacking.

The first objective of our work was to characterize the lymphatic transport of fluorescent polystyrene particles of $100 \mathrm{~nm}, 1 \mu \mathrm{m}$ and $10 \mu \mathrm{m}$ subcutaneously injected into the breast area of healthy and VX2 tumor-bearing rabbits.

We choose the rabbit model for the current study because of the resemblances with humans regarding the lymphatic drainage of the mammary gland. In female rabbit the thoracic mammary gland is drained by two groups of axillary LN, dorsal accessory and ventral accessory. In woman, as in rabbit, the mammary gland is drained by two groups of axillary LN: pectoral and apical, which corresponds to axillary accessory ventral and dorsal LN in female rabbit (32).The VX2 tumor is an anaplastic squamous cell carcinoma highly malignant that metastasize mainly to LN and lung and rarely to other sites (33). Despite the different origin compared to human breast carcinoma, VX2 tumors share some common characteristics such as: the way to metastasize, chemosensitivity to the therapeutic drugs and tumor growth and angiogenesis. Both tumors spread mainly by lymphatic way $(11,33)$, which means that the first sites of metastasis are the LN that drained the tumors. For these reasons the VX2 model is currently used to study nanoparticulate drugs and contrast media for imaging and therapy of sentinel LN in breast and oropharyngeal cancer $(10,20,21,34)$. VX2 cells are highly sensitive to doxorubicin (35), which is the classic drug in conventional adjuvant and neoadjuvant chemotherapy in breast cancer in women.

Moreover, as in many human breast carcinoma (36), in VX2 tumors VEGF is an important factor promoting tumor growth and angiogenesis (37).

We further aimed to use the same methods as used in practice to diagnose the breast cancer in women. The routine checkup for the breast in women is currently performed by ultrasound. The setting up of the real diagnostic conditions in an animal model is difficult in rodents due to their small size. For 
above mentioned reasons we considered that rabbit bearing breast tumors could be an appropriate model for lymphotherapy.

This model will allow us to compare the lymphatic transport of the two types of microspheres (MS) to polystyrene nanospheres (100nm), which were used as positive control for LN uptake. Then, in both the healthy and metastatic LN, we quantified the area occupied by fluorescent material five days after the subcutaneous injection. During this work a particular attention was paid to investigate the location of microspheres in relation to the tumor cells in the invaded LN. We questioned whether the presence of metastases into the draining LN could influence the transport of the MS into the sentinel LN and in addition the distribution of MS into the LN. The comprehension of the kinetic of transport and location of the $1 \mu \mathrm{m}$ and $10 \mu \mathrm{m}$ MS into the SLN could help in the choice of an effective drug carrier for lymphatic therapy.

\section{Material and methods}

\section{Fluorescent particles}

Carboxylated polystyrene microparticles conjugated with fluorescein (Fluoresbrite, Polyscience Inc, Warrington,USA Corporate) of different sizes: 100nm (Catalog \# 16662-10), $1 \mu \mathrm{m}$ (Catalog\#1570210), and $10 \mu \mathrm{m}$ (Catalog\#18142-2) were used for LN tracking. Suspension of each particle size $(100 \mathrm{~nm}, 1 \mu \mathrm{m}$ and $10 \mu \mathrm{m})$ contains $4.5 \times 10^{13}, 4.5 \times 10^{11}$ and $4.5 \times 10^{7}$ particles $/ \mathrm{mL}$, respectively. The experimental procedures were performed at the Center of Research in Interventional Radiology (Cr2i/APHP/ National Institute of Agronomic Research INRA; Jouy-en-Josas, France). Ethics approval number 08-008 was obtained from the Institutional Animal Care and Use Committee of the Center and was conducted according to European Community rules of animal care (Directive EC 86/609). The research adhered to the "Principles of Laboratory Animal Care"' (NIH publication \#8523, revised in 1985).

\section{Animal and tumor growth}

Nine White New Zealand adult female rabbits (6 months age, weight $3.4 \mathrm{~kg} \pm 0.28$ ) were selected for tumor implantation. Rabbit VX2 carcinoma, a squamous epithelioid carcinoma with rapid growth, was 
used to create breast tumours (33). The VX2 tumor was serially passed into a hind paw of White New Zealand rabbits. A 15 days hind paw tumor was aseptically harvested in phosphate buffered saline (PBS) containing $1 \%$ fetal calf serum. Tumor was fragmented, cautiously pressed through a nylon sieve (mesh size $200 \mu \mathrm{m}$ ), collected in ice-cold RPMI 1640 medium, centrifuged, and the cellular depot was used as inoculum. The rabbits were pre-anesthetized with an intramuscular injection of $30 \mu \mathrm{g} / \mathrm{kg}$ Buprenorphine (Vetergesic®, Sogeval, Laval, France). General anesthesia was performed by a short flash mask anesthesia with 2-3\% Isoflurane and 97-98\% oxygen using a small animal anesthesia station (Hallowell EMC Model AWS, Pittsfield, USA). After randomization, animals were placed in a supine position and the thoracic area was carefully shaved and disinfected. A volume of $0.2 \mathrm{ml}$ of cellular suspension corresponding to $50 \times 10^{6}$ cells was injected deep under the nipple of one thoracic mammary gland. The tumor was grown for 15 days. Tumor and LN size (length and width) was measured by ultrasound at D9, D15 and D20 with a 5-mHz abdominal transducer (Voluson E8 Expert, GE Healthcare, CA, USA). The measurements of the LN were performed on the most superficial LN, the accessory dorsal axillary which was easily detectable by US thanks to its location into a mass of adipose tissue near the external flexion of dorsal thoracic vein (32).

\section{Subcutaneous injection of nanospheres and microspheres}

Fifteen days after the implantation of VX2 cells, the animals were anesthetized as described earlier. After randomization, $0.2 \mathrm{ml}$ of particle suspension of 100nm (group A, n=3), 1 $\mu \mathrm{m}$ (group B, $\mathrm{n}=3$ ) and $10 \mu \mathrm{m}$ (group $\mathrm{C}, \mathrm{n}=3$ ) were injected subcutaneously in 4 points $(50 \mu 1 /$ point), around the nipple, in the healthy and tumor mammary gland in each animal.

\section{Tumors and lymph nodes recovery}

Five days after the particles injection animals were anesthetized as described before, by a short flash mask anesthesia with 2-3\% Isoflurane and 97-98\% oxygen. The axillary LN were tracked using $0.2 \mathrm{ml}$ Bleu Patenté V sodique (Guerbet, Roissy Charles de Gaulle Cedex, France) injected around the nipple of each thoracic mammary gland. Two LN could drain the mammary thoracic gland in rabbit: the first LN is the accessory dorsal axillary which is the most superficial and could be palpated and the second 
$\mathrm{LN}$ is the accessory ventral axillar which is more profound and could not be palpated (32). Euthanasia was performed with $5 \mathrm{ml}$ Pentobarbital, $182.2 \mathrm{mg} / \mathrm{ml}$ (Dolethal, Vetoquinol, Lure, France) injected into the marginal vein of the ear. Tumors and LN were carefully dissected and the length and the width were measured with a calliper. The LN and small pieces of skin at the injection site were embedded and snap-frozen in a matrix gel for cryostat sectioning (Sakura Finetek SAS, Villeneuved'Ascq, France) and the tumors were fixed in $4 \%$ formaldehyde solution. The volume was calculated according to the formula: $\mathrm{V}=\mathrm{Lxl}^{2} \mathrm{x} \pi / 6$, were $\mathrm{L}$ stand for length and 1 for width. Specimen slices $(6 \mu \mathrm{m}$ and 10 thick) parallel to the long diameter of each LN and axial into the skin samples were performed with a cryostat Leica (CM3050S, Nussloch, Germany) and were fixed in cold methanol/acetone (1/1) for 20 min. The slides were examined by epifluorescence microscopy to evaluate the distribution of particles into the LN. One slide from each LN was used for the metastases labeling by immunohistochemistry.

\section{Epifluorescence Microscopy}

Epifluorescence analysis was performed with a Leica Leitz DMBR microscope system to assess the distribution of the particles along the $\mathrm{LN}$ area and to observe the presence of the particles at the injection sites. Slides were stained with DAPI (4',6-diamidino-2-phenylindole) (Thermo Fisher Scientific Inc), mounted with Vectashield mounting medium (Vector Laboratories, Burlingame, CA, USA) and examined under x100 magnification for particle detection.

\section{Immunohistochemistry for metastases detection in $L N$}

The slides were incubated with mouse IgGlanti-human cytokeratin monoclonal antibody (mAb) (clone AE1/AE3, Dako), diluted at 1/50 and then with a HRP horse anti-mouse IgG Ab (Vector Laboratories, Burlingham, CA, US) for $30 \mathrm{~min}$ at room temperature. Revelation was performed with 3'3-diaminobenzidine substrate. Stained sections were then digitized with a slide scanner (NanoZoomer 2.0 HT; Hamamatsu, Hamamatsu City, Japan) at magnification $\times 20$. The surface of cytokeratin staining was assessed on each digitized section using the NDP view2 U12388-01 viewing software (Hamamatsu Photonics, Hamamatsu City, Japan). Surface of metastasis was expressed as percentage of stained area from the total $\mathrm{LN}$ area. 


\section{Confocal microscopy for location and quantification of fluorescence in different regions of $L N$}

Slides of $10 \mu \mathrm{m}$ tick were used to quantify the area of fluorescent particles and to analyse the location of the particles into the metastatic, pathologic and healthy LN. The slices from LN identified as positives for metastases by IHC were stained with mouse IgG1 anti-human cytokeratin mAb, clone AE1/AE3 (Dako, Glostrup, Denmark), diluted at 1/50, or with irrelevant murine IgG1 (control), and then with goat anti-mouse IgG Alexa Fluor 647 conjugate at 1/200 dilution for $30 \mathrm{~min}$. Slides from healthy LN were stained for actin to emphasize the cytoplasm with Phalloidin Alexa Fluor 594 conjugate, diluted at 1/50, for $20 \mathrm{~min}$. Secondary conjugate and control IgG1 Ab were purchased from Thermo Fisher Scientific Inc. Nuclei were stained with $1 \mu \mathrm{M}$ TO-PRO®3 (Thermo Fisher Scientific Inc) for $15 \mathrm{~min}$. Samples were mounted with Vectashield Mounting Medium and examined using a confocal laser-scanning microscope LSM 700 Axio Observer (Karl Zeiss Microscopy, Jena, Germany), using Plan Apochromat 20x/0.8 and 63x/1.4 Oil M27 objective lens. Green fluorescence and red fluorescence were excited with Argon laser lines at 488 and 639nm respectively and emissions were collected at 518 and $660 \mathrm{~nm}$. The images were captured in "hot spot" area of green particles in healthy $\mathrm{LN}$, in tumor $\mathrm{LN}$ that were negative for cytokeratin (non metastatic $\mathrm{LN}$ ) and in $\mathrm{LN}$ cytokeratin positives (metastatic LN). For the metastatic LN, images were captured in three different region of interest: in the non-metastatic area, in the border area between healthy and area invaded by malignant cells, and in the area completely invaded by tumor cells. Pictures were captured and analysed by ZEN 2.3 software (Karl Zeiss Microscopy, Munchen, Germany). The pictures with autofluorescent macrophages were excluded and the surface of fluorescent particles was automatically quantified using Image J software (Image J, $1.42 \mathrm{~s}$, National Institutes of Health, USA) and expressed as a ratio between the green fluorescent area and the total analysed area in each field $(\mathrm{nm} 2 / \mu \mathrm{m} 2)$. In order to validate the measurements of the fluorescent area and to exclude any bias introduced by the different intensities of fluorescence between particles, the diameter of the isolated particles and the intensity of 
fluorescence were measured on five particles of $1 \mu \mathrm{m}$ and $10 \mu \mathrm{m}$ and on five isolated clusters of $0.1 \mu \mathrm{m}$ and $1 \mu \mathrm{m}$ by ZEN 2.3 software, into the healthy LN (Fig. S1 and S2, supplementary data).

\section{Statistics}

The statistical analyses (Stat View version 5.0; SAS Institute, Inc, Cary, North Carolina) included a nonparametric Mann-Whitney U test (MW) and Kruskal Wallis test (KW) to compare the tumor volume between the different time points, the LN volume between healthy and tumor side, and the fluorescent area occupied by particles in the LN. Results were considered significant when $p<0.05$. The Spearman correlation test was used to determine if some parameters like LN volume and the percentage of the LN metastases are correlated. Results were considered significant when $\mathrm{p}<0.05$ and Rho> 0.500 .

\section{Results}

Tumor growth and LN volume

All animals developed a tumor palpable and measurable by US starting with D9. Tumor volume was significantly higher at D9, D15 and D20 when compared each time point with the previous one (D15/D9, p<0.0003 and D20/D15, p<0.0380) (Fig. 1a). The accessory dorsal axillary LN could be palpated when its diameter was superior to $0.5 \mathrm{~cm}$, usually from $\mathrm{D} 9$ on the tumor side. The contralateral LN, on the healthy side, had a diameter which in most cases was inferior to $5 \mathrm{~mm}$, thus it cannot be always palpated.

LN volume measured by US was significantly higher for the LN located on tumor side compared to contralateral healthy LN at D9 (p<0.0090), D15 (p<0.0053) and D20 ( $<<0.0184)$ (Fig.1b). At the moment of the microspheres injection there were no significant differences between animals neither for tumor $(\mathrm{p}<0.4335, \mathrm{KW})$ nor for pathologic and healthy $\mathrm{LN}$ volume $(\mathrm{p}<0.4335, \mathrm{KW})$.

Five days after the subcutaneous injection of fluorescent particles, $18 \mathrm{LN}$ were collected during dissection on the tumor side and 12 on the healthy side. The first LN, accessory dorsal axillary was found in all animals on each side. The second LN (accessory ventral axillary) was collected on the healthy side only in two animals from the 100nm group and in one animal from $10 \mu \mathrm{m}$ group. On the 
tumor side the second LN was found for all animals excepting one animal from 100nm group. The LN volumes determined by caliper were positively correlated with $\mathrm{LN}$ volumes measured by ultrasound at D20 (Rho=0.632, $\mathrm{p}<0.0092)$. No metastases in lungs or in abdominal organs/cavity were observed for any animals in the study.

\section{Immunohistochemistry for metastases evaluation into the $L N$}

Metastases (positive cytokeratin labelling) (Fig. 2a, 2b) were found in $7 \mathrm{LN}$ over the 18 collected on the tumor side: $4 \mathrm{LN}$ from 5 in the $100 \mathrm{~nm}$ group, $2 \mathrm{LN}$ from 6 in the $1 \mu \mathrm{m}$ MS group and one LN from 7 in the $10 \mu \mathrm{m}$ MS group.

Taken together these $\mathrm{LN}$ belong to 5 out of 9 primary breast tumors $(55 \%)$. The metastases were systematically found into the first LN except for one animal of the $1 \mu \mathrm{m}$ MS group, for which only the second $\mathrm{LN}$ was positive for metastasis. For two animals (one from $100 \mathrm{~nm}$ and one from $1 \mu \mathrm{m}$ group) the metastases invaded the first and the second LN. Variable ratios of metastases invasion were observed into the LN, from $0.05 \%$ to $100 \%$ of LN surface (Fig 2 and 3). Malignant cells invaded the cortex (LN weakly invaded) (Fig. 2c), or the cortex and medulla (LN strongly invaded) and replaced the normal structure of the LN (Fig. 2d).

The surface of LN occupied by the metastases was significantly higher for the LN of the 100nm group $(36.6 \% \pm 44)$ when compared to the $10 \mu \mathrm{m}$ group $(0.007 \% \pm 0.019, \mathrm{p}<0.0348)$ but not different for the $1 \mu \mathrm{m}$ group $(10.46 \% \pm 17.7, \mathrm{p}<0.2012)$ (Fig.3a).

The volume of metastatic LN $\left(0.565 \pm 0.538 \mathrm{~cm}^{3}\right)$ was significantly higher than the volume of pathologic non metastatic LN $\left(0.326 \pm 0.491 \mathrm{~cm}^{3}\right)(\mathrm{p}<0.0463)$ and the volume of healthy $\mathrm{LN}(0.042$ $\left.\pm 0.035 \mathrm{~cm}^{3}\right)(\mathrm{p}<0.0004)$ (Fig. 3b). The volume of healthy LN was smaller than the volume of pathologic LN non-invaded by tumor cells $(\mathrm{p}<0.0019)$. A positive correlation between the percentage of metastases and LN volume was found $(\mathrm{Rho}=0.515, \mathrm{p}=0.0194)$.

\section{Distribution of the microparticles at the injection site and into the healthy $L N$}


Microspheres and nanospheres were still present at the injection sites several days after injection. They are surrounded by an infiltrate of inflammatory cells suggesting that transport to the LN remained possible (Fig. S3, Supplementary data).

Nanoparticles (100nm) were observed as clusters in the cortex, in subcapsular sinus and less frequent into the medulla of all LN from healthy side (5/5), associated to the cells with bean shaped nuclei (Fig. 4a, b). The $1 \mu \mathrm{m}$ MS were present in all the LN from the healthy side, as rare single particle or small clusters composed of 2 to $5 \mathrm{MS}$ and as large numerous clusters containing 5 to 20MS (Fig. 4c). The small clusters were observed mostly into the cortex in the vicinity of the cells with reniform nucleus. The large clusters were more frequently observed into the deep cortex and medulla and were associated with the cells having big round nuclei (Fig. 4c, d). The MS of $10 \mu \mathrm{m}$ diameter were rare into the healthy LN and distributed as single particles into the deep cortex and as small clusters (2-3MS) into the medulla of LN, associated to cells with big round nuclei (Fig.4 e, f).

\section{Location of fluorescent particles in invaded LN in relation to tumor cells by confocal microscopy.}

Into the healthy LN the nanoparticles (100nm) were distributed more or less densely according to the zone of the LN (Fig.5A), as described earlier. Into the metastatic LN the nanoparticles (100nm) were distributed numerously into healthy area (Fig. 5B), their presence seemed to diminish with the increasing number of tumor cells (Fig. 5C), so that into the fully invaded area they were absent or very rare (Fig. 5D). The MS of $1 \mu \mathrm{m}$ are distributed into the healthy $\mathrm{LN}$ all over tissue slide (Fig. 6A) as described previously. At the opposite, into the metastatic LN they were numerous into the area without metastases (Fig. 6B) and into the area bordering the zone of metastases (Fig. 6C) but they were very rare or missing into the fully invaded area of the LN (Fig. 6D).

\section{Quantification of the fluorescence area in the $L N$ in relation with the metastatic invasion}

In order to validate the measurements of the fluorescent area and to exclude any bias introduced by the different intensities of fluorescence between particles, the diameter of the isolated particles and the intensity of fluorescence were measured on five particles of $1 \mu \mathrm{m}$ and $10 \mu \mathrm{m}$ and on five isolated clusters of $0.1 \mu \mathrm{m}$ and $1 \mu \mathrm{m}$ by ZEN 2.3 software, into the healthy LN (Fig. S1 and S2, supplementary 
data). The size of the particles measured by Zen Lite software was the same with the size indicated by the manufacturer $(1.015 \pm 0.072 \mu \mathrm{m}$ for $1 \mu \mathrm{m}$ MS and $10.35 \pm 0.19 \mu \mathrm{m}$ for $10 \mu \mathrm{m}$ MS) (Fig. S1supplementary data). The intensity of the fluorescence was not different nor between $1 \mu \mathrm{m}$ and $10 \mu \mathrm{m}$ particles $(252 \pm 6,8$ vs 255$)(\mathrm{p}<0,1100$, MW) (Fig. S1-supplementary data), neither between clusters of $0.1 \mu \mathrm{m}$ and $1 \mu \mathrm{m}(222.6 \pm 28$ vs $215.8 \pm 33)(\mathrm{p}<0.1116, \mathrm{MW})$ (Fig. S2-Supplementary data). These data provethe accuracy of the measurements of the fluorescent area for the quantification of the particles of different sizes located in the lymph nodes

In order to quantify the amount of particles located in the LNs 5 days after subcutaneous injection, the area occupied by fluorescent particles was measured into the healthy LN and into the LN collected from the tumor side: LN devoid of metastases and invaded LN. Into the invaded LN three regions were analyzed: area without tumor cells, area with scattered tumor cells bordering the fully invaded area and the fully invaded area (Fig. 7). In the $100 \mathrm{~nm}$ group, the fluorescent surface was higher in the healthy LN compared to the area fully invaded by tumor cells of the metastatic $\mathrm{LN}$ ( $\mathrm{p}<0.0339$, MW). Within the tumor LN, the surface of fluorescence measured in the area fully invaded by tumor cells was significantly lower than into the region free of metastases $(\mathrm{p}<0.0433, \mathrm{MW})$ or than in the tumor non-invaded LN (0.0433, MW). A similar distribution of fluorescence was measured in the LN regions for the $1 \mu \mathrm{m}$ MS. A small fluorescent surface was measured in the area fully invaded by tumor cells compared to the weakly invaded region $(\mathrm{p}<0.0143, \mathrm{MW})$ or to noninvaded region of the metastatic LN ( $<<0.0500, \mathrm{MW})$. In these two last regions of invaded LN, the surface occupied by MS was close to the value determined in the healthy $\mathrm{LN}(\mathrm{p}<0.5637$ and $\mathrm{p}<0.7728$ respectively). The surface occupied by $1 \mu \mathrm{m}$ MS in the invaded LN (area without metastases and weakly invaded) was 22 and 25 fold higher than the fluorescent surface measured in the $100 \mathrm{~nm}$ group in the correspondent area. In the $10 \mu \mathrm{m}$ MS group, the effect of tumor cells invasion on MS distribution was not studied because only one LN was positive for metastases, the rate of invasion was very low (micrometasases) and in this LN no MS were detected. The surface occupied by $10 \mu \mathrm{m}$ MS in the tumor non-invaded LN was higher compared to the healthy $\mathrm{LN}(\mathrm{p}<0.0209$, MW), suggesting a better drainage and retention in the LN of the tumor side. 


\section{Discussion}

The aim of our study was to compare the lymphatic transport of fluorescent particles of different sizes in healthy and metastatic lymph nodes when injected subcutaneously, into the breast area of healthy and tumor-bearing rabbits. The second objective was to investigate the location of the particles in the $\mathrm{LN}$ in relation to tumor cells and to quantify the particle uptake in different regions of invaded LN. To this end, we use a VX2 model currently employed to study nanoparticulate contrast media for imaging and therapy of sentinel LN in breast and oropharyngeal cancer $(10,20,21,34)$. We chose negatively charged polystyrene microspheres as they allow a better uptake and retention into the $\mathrm{LN}(2,31)$ and they represent a model for the negatively charged MS clinically used for local drug delivery (38). We demonstrate here that microspheres of $1 \mu \mathrm{m}$ and $10 \mu \mathrm{m}$ diameter were strongly drained by the pathologic LN. After LN uptake, the $1 \mu \mathrm{m}$ microspheres were located in close contact with metastatic regions but were very rare into the core of the tumoral zone.

\section{Tumor model and metastases invasion of $L N$}

After 20 days of tumor development we used a model of metastatic breast cancer from which we observed $18 \mathrm{LN}$ for 9 breast tumors. From the 18 pathologic LN, $39 \%(7 / 18)$ were metastatic and $61 \%(11 / 18)$ were negative for metastases as detected by cytokeratin labeling. We found that the LN on the tumor side, metastatic or not, were significantly larger and 1.5 fold more numerous than those from the healthy side. Our results are in line with the reports of Junping and coworkers about a VX2 breast tumor model (39). After 30 days of tumor development they reported that, out of $70 \mathrm{LN}$ for 60 tumors, $58 \%$ of the LN were metastatic and $42 \%$ were not metastatic, both types being enlarged compared to healthy LN. These findings are consistent with our results and suggest that the metastatic process could begin with the lymphatic changes in the structure of LN responsible for their enlargement, and is followed by the tumor cell migration to the LN (2). The metastatic potential could depend on many factors as tumor age (39), size of the tumors (40) and tumor capacity to produce vascular growth factors (3)(39). In our study the tumors were younger, which could explain the smaller percentage of metastatic LN (39\%) compared to the Junping reports on VX2 breast tumor. 
Unexpectedly, we observed that the type of the injected particle had an effect on the level of metastases in LN, being significantly higher in the nanoparticles group and almost absent in $10 \mu \mathrm{m} \mathrm{MS}$ group. It seems that some factors interfered with the mechanism involved in the diffusion of the metastases toward the $\mathrm{LN}$ in the case of MS of $10 \mu \mathrm{m}$ and not in the case of nanoparticles and $1 \mu \mathrm{m}$ MS. It was speculated that the tumor-associated lymphatics and draining LNs are key modulators of tumor cell migration and invasion by mechanisms that remain unclear (41). Furthermore, the cells migrating to the LN could have an effect on lymphatic permeability in case of inflammatory conditions (42). We supposed that the injection of $10 \mu \mathrm{m}$ MS generated a local environment that hindered the metastatic process to the LN (inflammation, perturbed lymphatic permeability).

\section{Particle uptake by the healthy $L N$}

All the healthy LN contained the $100 \mathrm{~nm}$ particles, but the surface occupied was almost three times less important than observed for the MS of $1 \mu \mathrm{m}$ diameter. Others have already noticed the poor LN uptake of the nanocarriers of size inferior to $100 \mathrm{~nm}$ subcutaneously injected (12-14). These findings could be explained by a washout phenomenon of the nanoparticles that travel freely into the lymph and exit rapidly from the LN by efferent lymphatics into the first hours after injection. Unlike nanoparticles, the microspheres larger than $1 \mu \mathrm{m}$ injected via the submucosal $(22,23)$ or subcutaneous route $(24)$ are more efficiently retained by the LN than nanoparticles. Our results are in line with these observations, sustaining an enhanced $\mathrm{LN}$ uptake of the microspheres of $1 \mu \mathrm{m}$ and $10 \mu \mathrm{m}$ versus nanoparticles. We observed that the distribution of the nanoparticles and $1 \mu \mathrm{m}$ MS into the healthy LN is broadly similar to that described in other studies on lymphatic transport of the polystyrene particles after subcutaneous injection. Nanoparticles were concentrated into the subcapsular and follicular zone of the LN and $1 \mu \mathrm{m}$ MS preferentially located into the paracortex and medulla. Previous studies demonstrated that according to their size, particles target distinct populations of inflammatory cells and occupy distinct areas of the LN 8 days after subcutaneous injection into the mice foot pad (8). Small particles $<200 \mathrm{~nm}$ could be drained freely to the $\mathrm{LN}$ where they are associated with the resident macrophages and are

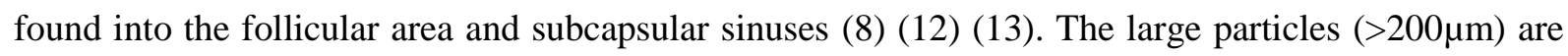


almost exclusively transported to the LN by dendritic cells (DC) and are found into the DC-rich area of the LN such as paracortex and medulla (8). According to these previous studies we can assume that the cells with big round nuclei that transported the large clusters of $1 \mu \mathrm{m}$ MS and the $10 \mu \mathrm{m}$ MS are probably DC. The clusters of nanoparticles and the small clusters of $1 \mu \mathrm{m}$ MS were probably flowing freely across the lymphatics and were phagocytized by the cells with reniform, alongated nuclei that are the resident macrophages in the LN. The differentiated distribution of the nanoparticles, $1 \mu \mathrm{m}$ and $10 \mu \mathrm{m}$ MS into the healthy LN in our study was expected.

Size dependent LN uptake of microspheres after subcutaneous or submucosal injection was previously analyzed by others. Lymphatic capillaries measure $10-60 \mu \mathrm{m}$ in diameter (1) and the lymphatic transport through them depends exclusively on the extracellular matrix pressure, since they do not possess muscular fiber and valves that could aid in lymph propulsion (1). The upper size limit for lymphatic uptake after subcutaneous administration has not been strictly defined. It was reported that the maximal size for microspheres which could be drained into the LN after mucosal administration ranged between 5 to $10 \mu \mathrm{m}$, MS of $40 \mu \mathrm{m}$ were also found into the draining $\mathrm{LN}$ up to 6 months after the submucosal injection $(22,43)$. According to these studies, the transport of negatively charged fluorescent $1 \mu \mathrm{m}$ and $10 \mu \mathrm{m}$ MS in healthy $\mathrm{LN}$ after subcutaneous injection around the nipple was expected.

\section{Microspheres uptake by the pathologic LN and location in relation to tumor cells in the invaded LN}

Five days after injection near the tumor, the LN uptake of the nanospheres and the microspheres and their distribution in the $\mathrm{LN}$ were analysed. We observed that the MS of $10 \mu \mathrm{m}$ diameter were better drained into the pathologic LN than into the healthy ones, but we have no information about their location relative to the tumor cells because the metastatic process was probably delayed or interrupted in these LN. Closer to the tumor, a better lymphatic drainage and LN dilation constitute favorable conditions for an accumulation of $10 \mu \mathrm{m}$ MS in the pathologic LN. Future long running studies will be performed to elucidate if particles of $10 \mu \mathrm{m}$ reach the same areas into the metastatic $\mathrm{LN}$ as $1 \mu \mathrm{m}$ particles did and if they interfere somehow with metastatic process. 
Confocal microscopy observation indicates that the uptake of $100 \mathrm{~nm}$ and $1 \mu \mathrm{m}$ particles by invaded LN was similar between the different regions of invaded $\mathrm{LN}$ whereas the $10 \mu \mathrm{m}$ MS were only observed in the non-invaded LN. We observed that the fluorescent nanoparticles were found in all pathologic LN, excepting one LN completely invaded by the metastases. Our observation is in accordance with the clinical and preclinical trials with MRI contrast media targeting sentinel LN in breast tumors $(11,34,39)$. According to these studies the superparamagnetic iron nanoparticles (SPIO) were not observed into the metastatic area of axillary LN because the access of the macrophages that carry them is probably hindered in these areas whose structure is altered by the tumor cells.

Unlike the healthy LN, where the MS of $1 \mu \mathrm{m}$ diameter were spread all over the LN slide, in the metastatic LN draining the tumors they were found in the area without metastases and weakly invaded by malignant cells. In the $\mathrm{LN}$ regions massively invaded by tumor cells, few $1 \mu \mathrm{m}$ MS diameter were observed. Compared to the $100 \mathrm{~nm}$ nanospheres, the surface occupied by $1 \mu \mathrm{m}$ MS diameter in the area non-invaded or moderately invaded were 22 and 25 times more important. That suggests that $1 \mu \mathrm{m}$ particles were better retained by the $\mathrm{LN}$, whereas a large amount of nanoparticles were probably washout from the LN. A drug delivery from $1 \mu \mathrm{m}$ MS which have a better coverage of the LN draining the tumor could impregnate a larger volume of tissue compared to nano-sized devices. Indeed, the efficiency of the drug delivery to tumor area increases with the particle size, particles of $1 \mu \mathrm{m}$ and $2 \mu \mathrm{m}$ could deliver anticancer drugs to the tumor cells more efficiently than nanoparticles did as demonstrated in vitro (25) and in vivo (26). The significant remanence of micrometric sized MS in invaded LN could explain the reduction of metastases invasion observed in pleural lymph nodes after intrapleural implantation of microspheres $(\approx 3 \mu \mathrm{m}$ diameter) loaded with paclitaxel in a lung cancer model in rat [29]. The optimal size of particles used in lymph-target chemotherapy should be defined: small enough to avoid remaining at the implantation sites around the tumor, but big enough to be well retained in the regional lymph nodes. In our study, the absence of fluorescence into the fully invaded $\mathrm{LN}$, or in regions of the LN predominantly composed of metastases could be explained by a poor migration of inflammatory cells that could carry the $1 \mu \mathrm{m}$ MS. The invasion of LN by tumor cells probably changes locally the LN drainage precluding migration of cells containing the MS $(1,12,31)$. 
The location of the particles in relation to the metastasis density into the LN suggests that the subcutaneous injection of DDS around a tumor should be precocious so that the particles can reach the LN before metastasis invasion. If the tumor cells invasion of LN is too important, the particles would not be drained, which could compromise the effectiveness of an antitumor treatment.

\section{Conclusion}

The MS of $1 \mu \mathrm{m}$ and $10 \mu \mathrm{m}$ diameter were drained by the pathologic $\mathrm{LN}$ five days after injection around mammary tumor. MS were distributed according to the degree of metastases invasion, numerous in the area uninvaded by the tumor cells and rarely in the area completely invaded. MS of $1 \mu \mathrm{m}$ diameter cover more $\mathrm{LN}$ surface than the nanospheres, suggesting a better retention in the sentinel LN. Microspheres arrive numerously close to the metastatic area but they poorly penetrate it. These findings are valuable in lymphotherapy since an improvement of the remanence of the drugloaded MS in LN could provide a sustained drug delivery around the metastatic area of LN, preventing the spread of tumor cells.

\section{Limitations}

The number of animals per group was low which limited the statistic interpretation for some parameters such as the particles uptake by healthy and pathologic LN, or metastasis development into the $\mathrm{LN}$ according to type of particles injected. The delay for tumor development (5 days) was probably too short for study simultaneously the metastases invasion and the drainage of the 10 $\mu \mathrm{m}$ MS.

\section{Acknowledgements}

We thank Celine Urien from Molecular Virology and Immunology Laboratory and Pierre Adenot from the Microscopy and Imaging of the Microrganismes, Animals and Aliments Platform (MIMA2) from the French National Institut of Agricultural Research (INRA) Jouy en Josas for the technical support in confocal imaging acquisition. 


\section{Legend to figures}

Fig. 1 Evolution of tumor volume (a) and LN volume (b) in time measured by ultrasound. The measures were made on accessory axillary dorsal lymph node

Fig. 2 Cytokeratin staining of a lymph node $(a, b)$ showing the tumor cells (cytokeratin positive) invading the cortex of a metastatic LN. Cytokeratin positive cells (black arrow) are larger than the normal cells of LN (black arrowhead) (a), and they have a dark brown cytoplasm and blue nuclei (b). Macroscopic view of cytokeratin stained LN (c, d) showing the tumor area in brown invading the cortex (C) and medulla (M) of metastatic LN. Pictures on digitized slides represent a weakly invaded LN (19\%) that belongs to $100 \mathrm{~nm}$ group (c) and a strongly invaded LN (65\%) from $1 \mu \mathrm{m}$ group (d)

Fig. 3 Cytokeratin positive area, expressed as percentage from total lymph node surface was significantly larger for the $100 \mathrm{~nm}$ group compared to the $10 \mu \mathrm{m}$ group (a). At D20 the volume of metastatic LN measured with calliper was significantly larger than the volume of the non-metastatic and healthy LN (b)

Fig. 4 Confocal images showing the details of particles in healthy LN slices stained with TO-PRO3 for nuclei, in blue. Particles of 100nm were observed as patches in vicinity of bean shaped nuclei (arrow) into the cortex $(\mathrm{a}, \mathrm{b})$. MS of $1 \mu \mathrm{m}$ were observed as single MS or small clusters (white asterisk) in the vicinity of the cells with bean shaped nuclei. Large clusters (white star) were observed nearby the cells with big round nuclei; image captured into the deep cortex(c, d). MS of $10 \mu \mathrm{m}$ were surrounded by cells with big round nuclei; image captured into the deep cortex (e, f). Some cells are carrying the small parts of degraded MS (dotted arrow) (e)

Fig. 5 Location of green fluorescent particles of $100 \mathrm{~nm}$ into a healthy $\mathrm{LN}$ (a, b, c) and into a metastatic LN (d to l). In the healthy LN (A), the cytoplasm of the LN resident cells was stained with phalloidine-Alexa-594, in magenta color. The tumoral cells were stained in red with anti-cytokeratinantibodies and Alexa-fluor 647.Into the metastatic LN the particles were distributed according to the 
degree of metastases invasion, numerous in the area non-invaded by the tumoral cells (B-d,e,f) and rarely or absent in the area weakly (C-g,h,i) or completely invaded by the tumoral cells (white arrows) (D-j,k,l). The red and green staining images are merged (f,i,l). Bar at $10 \mu \mathrm{m}$

Fig. 6 Location of green fluorescent microspheres of $1 \mu \mathrm{m}$ into a healthy $\mathrm{LN}(\mathrm{a}, \mathrm{b}, \mathrm{c})$ and into a metastatic LN (d to l). For details of labeling, see figure 5 legend. Into the metastatic LN, the MS were distributed according to the degree of tumoral cells invasion, MS were numerous in the non-invaded regions $(\mathrm{B}-\mathrm{d}, \mathrm{e}, \mathrm{f})$ and in the area weakly invaded $(\mathrm{C}-\mathrm{g}, \mathrm{h}, \mathrm{i})$ and rarely or absent in the area completely invaded by the tumoral cells (white arrows) (D-j,k,l). The red and green staining images are merged $(\mathrm{f}, \mathrm{i}, 1)$. Bar at $10 \mu \mathrm{m}$

Fig. 7 Quantification of fluorescent area in healthy (A) and tumoral LN (B to E). The images captured at 300x magnification ( $n=4 /$ region of interest), were analysed in Image $J$ and the surface of fluorescent events was measured and expressed as a ratio between total fluorescent events area and total area of the image analyzed, in $\mathrm{nm}^{2} / \mu \mathrm{m}^{2}$. A-healthy $\mathrm{LN}, \mathrm{B}, \mathrm{C}$ and $\mathrm{D}$ - invaded $\mathrm{LN}$ : B-area without metastases, $\mathrm{C}$-area weakly invaded neighboring the metastatic zone, D-area fully invaded, E- tumoral noninvaded LN

Fig. S1-supplementary data. The intensity of the fluorescence and the diameter of the particles was analyzed with Zen Lite 2.3 Karl Zeiss Microscopy GmBH,2011 Software on 5 isolated $1 \mu \mathrm{m}(\mathrm{A}, \mathrm{B})$ and $10 \mu \mathrm{m}(\mathrm{C}, \mathrm{D})$ microspheres on confocal images from healthy lymphnodes stained with TO-PRO3 for nuclei. The size of the particles measured was close to the size indicated by the manufacturer $(1.015 \pm 0.072 \mu \mathrm{m}$ for $1 \mu \mathrm{m}$ MS and $10.35 \pm 0.19 \mu \mathrm{m}$ for $10 \mu \mathrm{m}$ MS) (B). The intensity of the fluorescence was not different between $1 \mu \mathrm{m}$ and $10 \mu \mathrm{m}$ particles $(252 \pm 6,8$ vs 255$)(\mathrm{p}<0,1100, \mathrm{MW})(\mathrm{D})$.

Fig. S2-supplementary data. The nanoparticles were found into the LN only as clusters and not as single particles (A).The intensity of the fluorescence and the diameter of clusters were analyzed with Zen Lite 2.3 Karl Zeiss Microscopy GmBH, 2011 Software on 5 isolated clusters of $0.1 \mu \mathrm{m}$ (A,B) and $1 \mu \mathrm{m}$ microspheres $(\mathrm{C}, \mathrm{D})$ on confocal images from healthy lymphnodes stained with TO-PRO3 for nuclei. The diameter of the $0.1 \mu \mathrm{m}$ clusters was $1.79 \pm 0.42$ and that corresponded to almost 17 
nanoparticles, each particle visualized on the intensity profile as peak of fluorescence (white arrow, figure A, B). The diameter of the $1 \mu \mathrm{m}$ clusters was $5 \pm 3.19 \mu \mathrm{m}$ and corresponded to clusters formed by 3-8 particles, each particle visualized on the fluorescence intensity profile as peak of fluorescence (white arrow, figure B,C). The intensity of the fluorescence was not different between the clusters of $0.1 \mu \mathrm{m}$ and $1 \mu \mathrm{m}(222.6 \pm 28$ vs $215.8 \pm 33)(\mathrm{p}<0.1116, \mathrm{MW})(\mathrm{D})$.

Fig. S3 At day 5 the skin was sampled and epifluorescence analysis was performed to observe the presence of the particles at the site of injection. Slides were stained with DAPI for nuclei and mounted with Vectashield mounting medium (Vector Laboratories, Burlingame, CA, USA) and examined under x100 magnification for particle detection.

The particles were still observed at the sites of injection surrounding the depot (Inj). Many nuclei were observed around the clusters of particles (arrowhead), they probably belong to the inflammatory cells that infiltrate the injection site. The nanoparticles were rather distributed as large patches (white star) than small patches (white asterisk) at the site of injection. Huge clusters of $1 \mu \mathrm{m}$ MS (white star) were observed nearby the injection site. The small clusters and $1 \mu \mathrm{m}$ single particles (arrows) were numerously and were scattered more distant from the injection site. The particles of $10 \mu \mathrm{m}$ were distributed around the depot as single particle (arrow) or small clusters formed by 2 MS (empty arrow).

\section{References}

1. Swartz MA, Skobe M. Lymphatic function, lymphangiogenesis, and cancer metastasis. Microsc Res Tech. 2001 Oct 15;55(2):92-9.

2. Proulx ST, Luciani P, Dieterich LC, Karaman S, Leroux J-C, Detmar M. Expansion of the lymphatic vasculature in cancer and inflammation: new opportunities for in vivo imaging and drug delivery. J Control Release Off J Control Release Soc. 2013 Dec 10;172(2):550-7. 
3. Hirakawa S, Brown LF, Kodama S, Paavonen K, Alitalo K, Detmar M. VEGF-C-induced lymphangiogenesis in sentinel lymph nodes promotes tumor metastasis to distant sites. Blood. 2007 Feb 1;109(3):1010-7.

4. Ashikaga T, Krag DN, Land SR, Julian TB, Anderson SJ, Brown AM, et al. Morbidity results from the NSABP B-32 trial comparing sentinel lymph node dissection versus axillary dissection. $\mathrm{J}$ Surg Oncol. 2010 Aug 1;102(2):111-8.

5. Ryan GM, Kaminskas LM, Porter CJH. Nano-chemotherapeutics: maximising lymphatic drug exposure to improve the treatment of lymph-metastatic cancers. J Control Release Off $\mathrm{J}$ Control Release Soc. 2014 Nov 10;193:241-56.

6. Trevaskis NL, Kaminskas LM, Porter CJH. From sewer to saviour - targeting the lymphatic system to promote drug exposure and activity. Nat Rev Drug Discov. 2015 Nov;14(11):781-803.

7. Shackney SE, McCormack GW, Cuchural GJ. Growth rate patterns of solid tumors and their relation to responsiveness to therapy: an analytical review. Ann Intern Med. 1978 Jul;89(1):107-21.

8. Manolova V, Flace A, Bauer M, Schwarz K, Saudan P, Bachmann MF. Nanoparticles target distinct dendritic cell populations according to their size. Eur J Immunol. 2008 May;38(5):1404-13.

9. Randolph GJ, Angeli V, Swartz MA. Dendritic-cell trafficking to lymph nodes through lymphatic vessels. Nat Rev Immunol. 2005 Aug;5(8):617-28.

10. Wang P, Xie X, Wang J, Shi Y, Shen N, Huang X. Ultra-small superparamagnetic iron oxide mediated magnetic hyperthermia in treatment of neck lymph node metastasis in rabbit pyriform sinus VX2 carcinoma. Tumour Biol J Int Soc Oncodevelopmental Biol Med. 2015 Sep;36(10):8035-40.

11. Johnson L, Pinder SE, Douek M. Deposition of superparamagnetic iron-oxide nanoparticles in axillary sentinel lymph nodes following subcutaneous injection. Histopathology. 2013 Feb;62(3):4816.

12. Oussoren C, Storm G. Liposomes to target the lymphatics by subcutaneous administration. Adv Drug Deliv Rev. 2001 Aug 23;50(1-2):143-56.

13. Kaminskas LM, Ascher DB, McLeod VM, Herold MJ, Le CP, Sloan EK, et al. PEGylation of interferon $\alpha 2$ improves lymphatic exposure after subcutaneous and intravenous administration and 
improves antitumour efficacy against lymphatic breast cancer metastases. J Control Release Off J Control Release Soc. 2013 Jun 10;168(2):200-8.

14. Luboldt W, Pinkert J, Matzky C, Wunderlich G, Kotzerke J. Radiopharmaceutical tracking of particles injected into tumors: a model to study clearance kinetics. Curr Drug Deliv. 2009 Jul;6(3):255-60.

15. Lu H, Li B, Kang Y, Jiang W, Huang Q, Chen Q, et al. Paclitaxel nanoparticle inhibits growth of ovarian cancer xenografts and enhances lymphatic targeting. Cancer Chemother Pharmacol. 2007 Feb;59(2):175-81.

16. Lu B, Xiong S-B, Yang H, Yin X-D, Zhao R-B. Mitoxantrone-loaded BSA nanospheres and chitosan nanospheres for local injection against breast cancer and its lymph node metastases. II: Tissue distribution and pharmacodynamics. Int J Pharm. 2006 Jan 13;307(2):175-81.

17. Liu R, Gilmore DM, Zubris KAV, Xu X, Catalano PJ, Padera RF, et al. Prevention of nodal metastases in breast cancer following the lymphatic migration of paclitaxel-loaded expansile nanoparticles. Biomaterials. 2013 Feb;34(7):1810-9.

18. Yang Q, Wang X, Chen J, Tian C, Li H, Chen Y-J, et al. A clinical study on regional lymphatic chemotherapy using an activated carbon nanoparticle-epirubicin in patients with breast cancer. Tumour Biol J Int Soc Oncodevelopmental Biol Med. 2012 Dec;33(6):2341-8.

19. Barenholz Y. Doxil®--the first FDA-approved nano-drug: lessons learned. J Control Release Off J Control Release Soc. 2012 Jun 10;160(2):117-34.

20. Chen J-H, Ling R, Yao Q, Li Y, Chen T, Wang Z, et al. Effect of small-sized liposomal Adriamycin administered by various routes on a metastatic breast cancer model. Endocr Relat Cancer. 2005 Mar;12(1):93-100.

21. Niu C, Wang Z, Lu G, Krupka TM, Sun Y, You Y, et al. Doxorubicin loaded superparamagnetic PLGA-iron oxide multifunctional microbubbles for dual-mode US/MR imaging and therapy of metastasis in lymph nodes. Biomaterials. 2013 Mar;34(9):2307-17.

22. Damgé C, Aprahamian M, Marchais H, Benoit JP, Pinget M. Intestinal absorption of PLAGA microspheres in the rat. J Anat. 1996 Dec;189 ( Pt 3):491-501. 
23. Lemperle G, Lappin PB, Stone C, Lemperle SM. Urethral bulking with polymethylmethacrylate microspheres for stress urinary incontinence: tissue persistence and safety studies in miniswine. Urology. 2011 Apr;77(4):1005.e1-7.

24. Ueno H, Hihara J, Shimizu K, Osaki A, Yamashita Y, Yoshida K, et al. Experimental study on fluorescent microspheres as a tracer for sentinel node detection. Anticancer Res. 2005 Apr;25(2A):821-5.

25. De S, Miller DW, Robinson DH. Effect of particle size of nanospheres and microspheres on the cellular-association and cytotoxicity of paclitaxel in 4T1 cells. Pharm Res. 2005 May;22(5):76675.

26. Chakravarthi SS, De S, Miller DW, Robinson DH. Comparison of anti-tumor efficacy of paclitaxel delivered in nano- and microparticles. Int J Pharm. 2010 Jan 4;383(1-2):37-44.

27. Narita K, Ikuta H, Hamabe Y, Kuroda Y. Experimental study on paratumoral injection of cisplatin-loaded microspheres for gastric cancer. Kobe J Med Sci. 1999 Oct;45(5):229-43.

28. Nakamura Y, Hamabe Y, Ikuta H, Hyon S-H, Kuroda Y. An experimental study of regional chemotherapy using CDDP-loaded microspheres for esophageal cancer. Surg Today. 2002;32(4):33542.

29. Liu J, Meisner D, Kwong E, Wu XY, Johnston MR. Translymphatic chemotherapy by intrapleural placement of gelatin sponge containing biodegradable Paclitaxel colloids controls lymphatic metastasis in lung cancer. Cancer Res. 2009 Feb 1;69(3):1174-81.

30. Hawley AE, Illum L, Davis SS. The effect of lymphatic oedema on the uptake of colloids to the lymph nodes. Biopharm Drug Dispos. 1998 Apr;19(3):193-7.

31. Hawley AE, Illum L, Davis SS. Lymph node localisation of biodegradable nanospheres surface modified with poloxamer and poloxamine block co-polymers. FEBS Lett. 1997 Jan 6;400(3):319-23.

32. Robert Barone. Système lymphatique du lapin dans "Anatomie comparée des mamiferes domestiques", page 845. Vigot Frères. Vol. Angiologie. Paris; 1996. 903 p.

33. Kidd JG, Rous P. A transplantable rabbit carcinoma originating in a virus-induced papilloma and containing the virus in masked or altered form. J Exp Med. 1940 May 31;71(6):813-38. 
34. Pouw JJ, Grootendorst MR, Bezooijen R, Klazen CAH, De Bruin WI, Klaase JM, et al. Preoperative sentinel lymph node localization in breast cancer with superparamagnetic iron oxide MRI: the SentiMAG Multicentre Trial imaging subprotocol. Br J Radiol. 2015;88(1056):20150634.

35. Pascale F, Bedouet L, Baylatry M, Namur J, Laurent A. Comparative Chemosensitivity of VX2 and HCC Cell Lines to Drugs Used in TACE. Anticancer Res. 2015 Dec;35(12):6497-503.

36. Yoshiji H, Gomez DE, Shibuya M, Thorgeirsson UP. Expression of vascular endothelial growth factor, its receptor, and other angiogenic factors in human breast cancer. Cancer Res. 1996 May 1;56(9):2013-6.

37. Pascale F, Ghegediban S-H, Bonneau M, Bedouet L, Namur J, Verret V, et al. Modified model of VX2 tumor overexpressing vascular endothelial growth factor. J Vasc Interv Radiol JVIR. 2012 Jun;23(6):809-817.e2.

38. Chao P, Deshmukh M, Kutscher HL, Gao D, Rajan SS, Hu P, et al. Pulmonary targeting microparticulate camptothecin delivery system: anticancer evaluation in a rat orthotopic lung cancer model. Anticancer Drugs. 2010 Jan;21(1):65-76.

39. Junping W, Tongguo S, Yunting Z, Chunshui Y, Renju B. Discrimination of axillary metastatic from nonmetastatic lymph nodes with PROPELLER diffusion-weighted MR imaging in a metastatic breast cancer model and its correlation with cellularity. J Magn Reson Imaging JMRI. 2012 Sep;36(3):624-31.

40. Veronesi U, Viale G, Paganelli G, Zurrida S, Luini A, Galimberti V, et al. Sentinel lymph node biopsy in breast cancer: ten-year results of a randomized controlled study. Ann Surg. 2010 Apr;251(4):595-600.

41. Ji R-C. Lymph Nodes and Cancer Metastasis: New Perspectives on the Role of Intranodal Lymphatic Sinuses. Int J Mol Sci. 2016 Dec 28;18(1).

42. Ivanov S, Scallan JP, Kim K-W, Werth K, Johnson MW, Saunders BT, et al. CCR7 and IRF4dependent dendritic cells regulate lymphatic collecting vessel permeability. J Clin Invest. 2016 Apr $1 ; 126(4): 1581-91$. 
43. Lemperle G, Lappin PB, Stone C, Lemperle SM. Urethral bulking with polymethylmethacrylate microspheres for stress urinary incontinence: tissue persistence and safety studies in miniswine. Urology. 2011 Apr;77(4):1005.e1-7. 
Fig.1
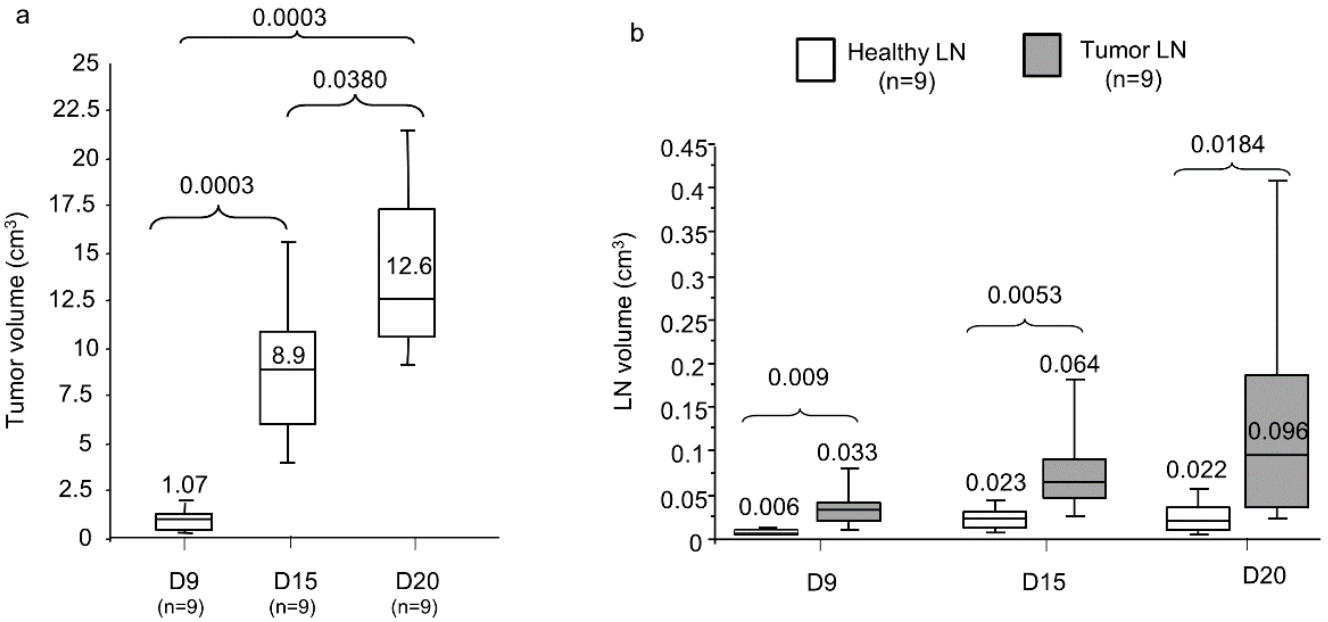

Fig.2
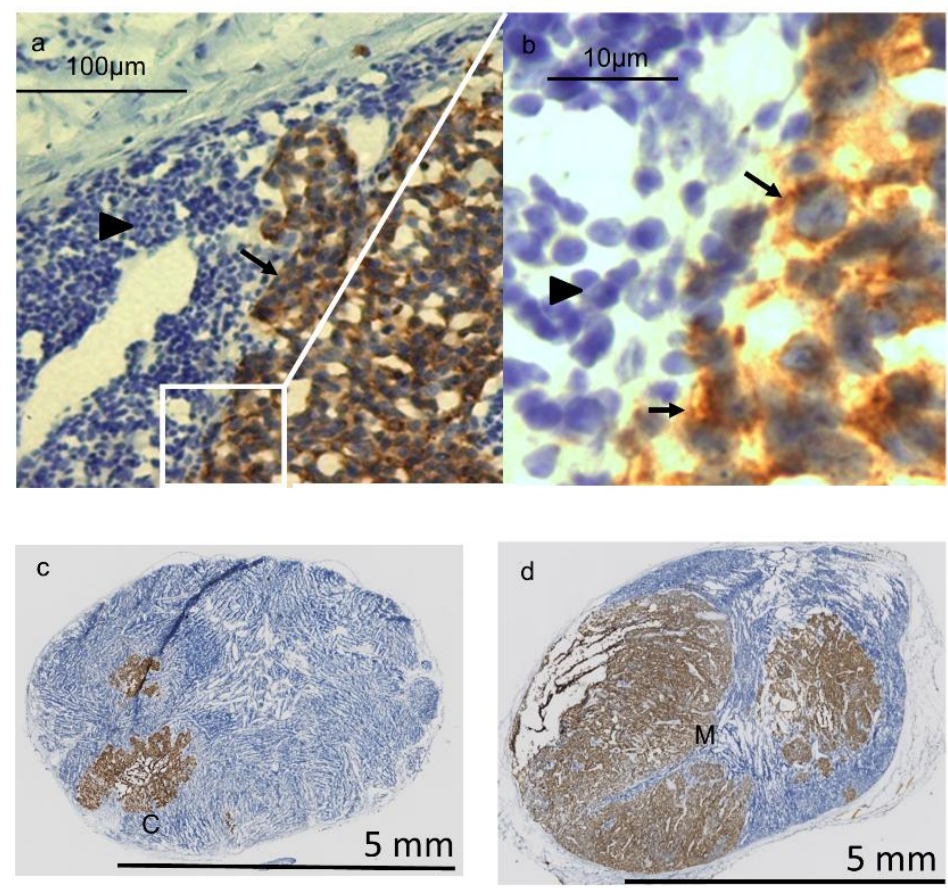
Fig. 3

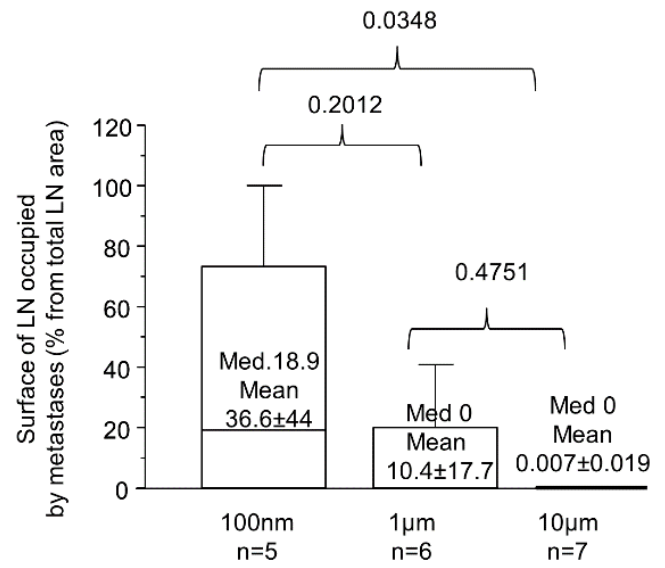

b

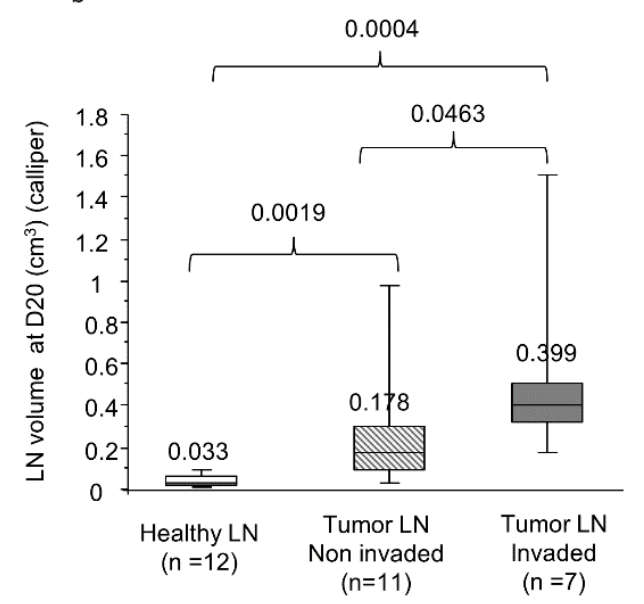

Fig.4

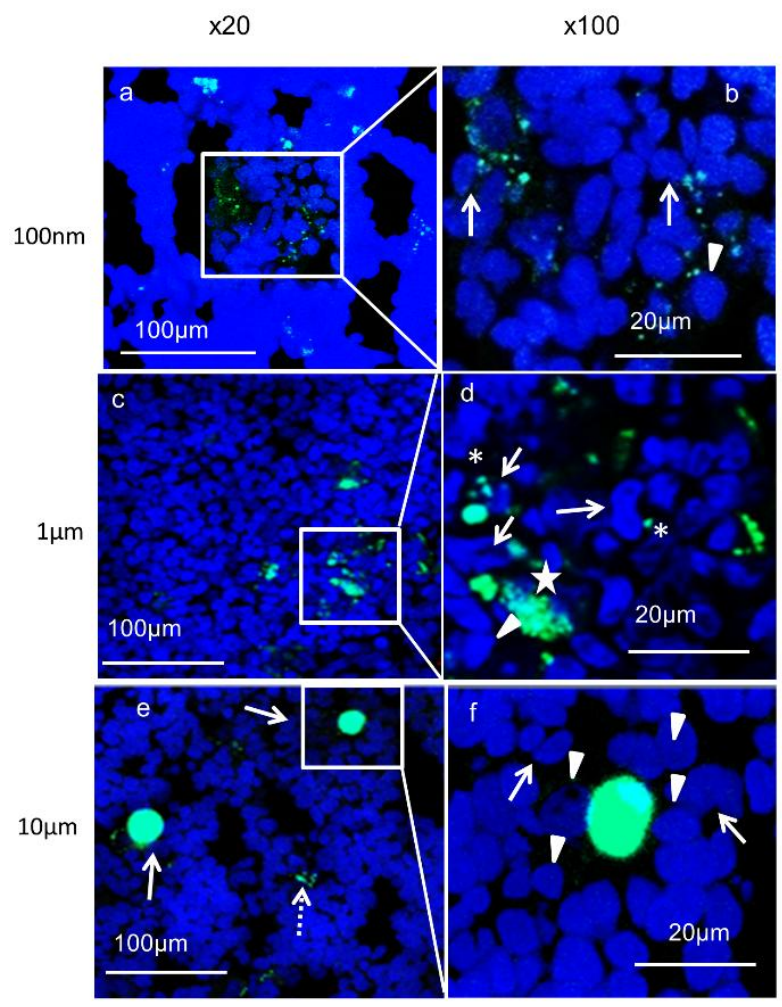


Fig.5
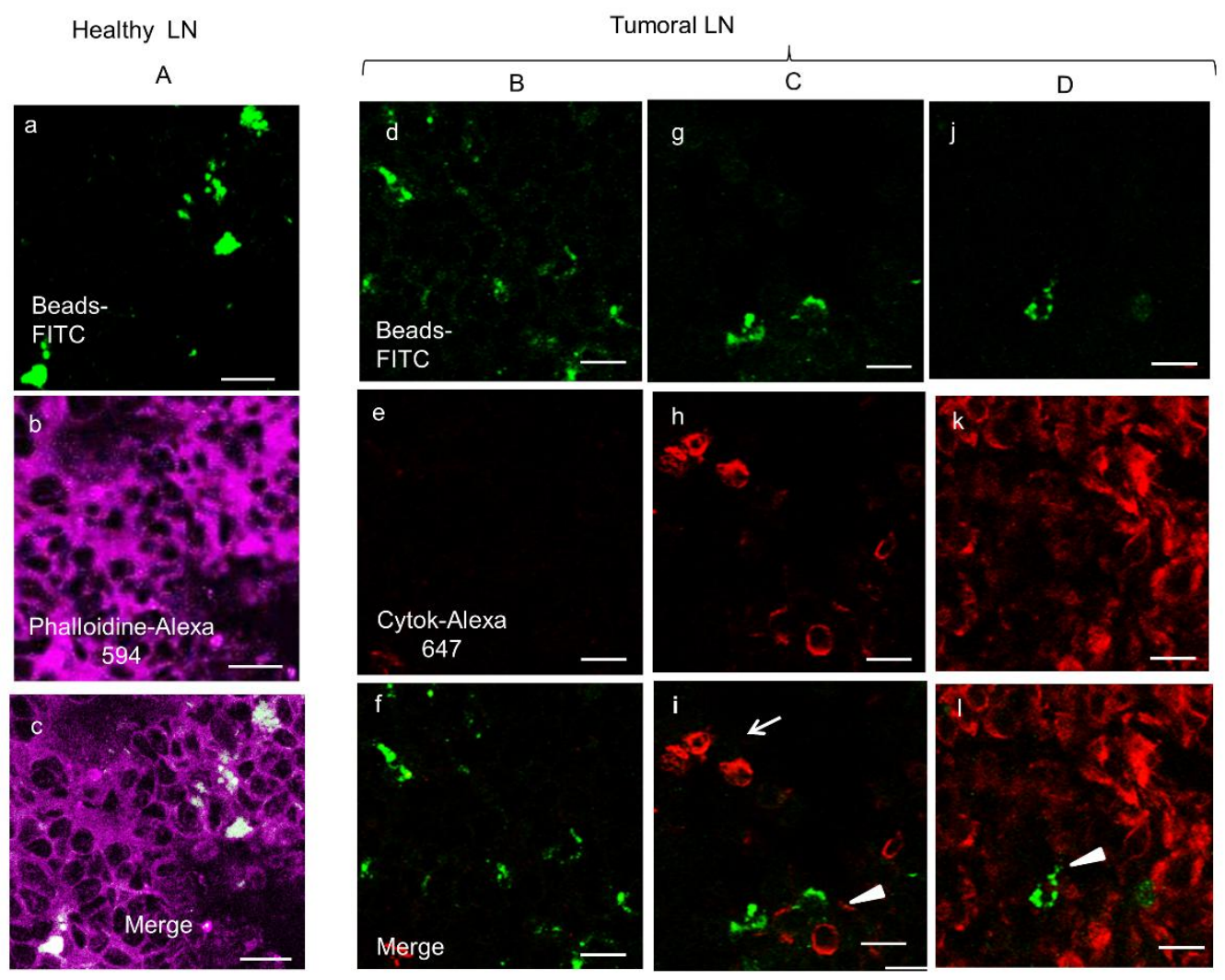

Fig.6

Healthy LN

A

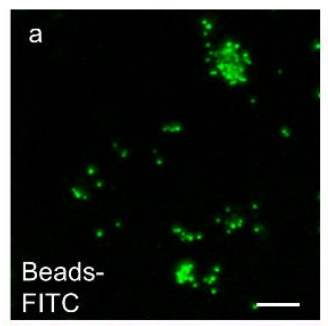

b

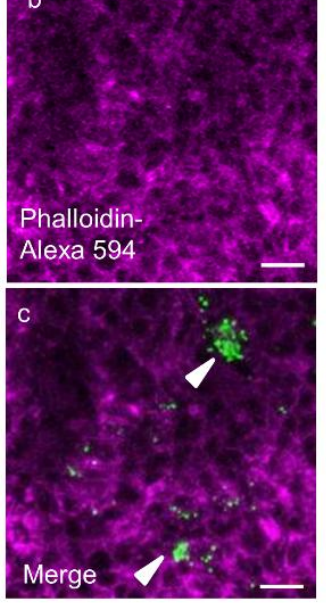

Tumoral LN

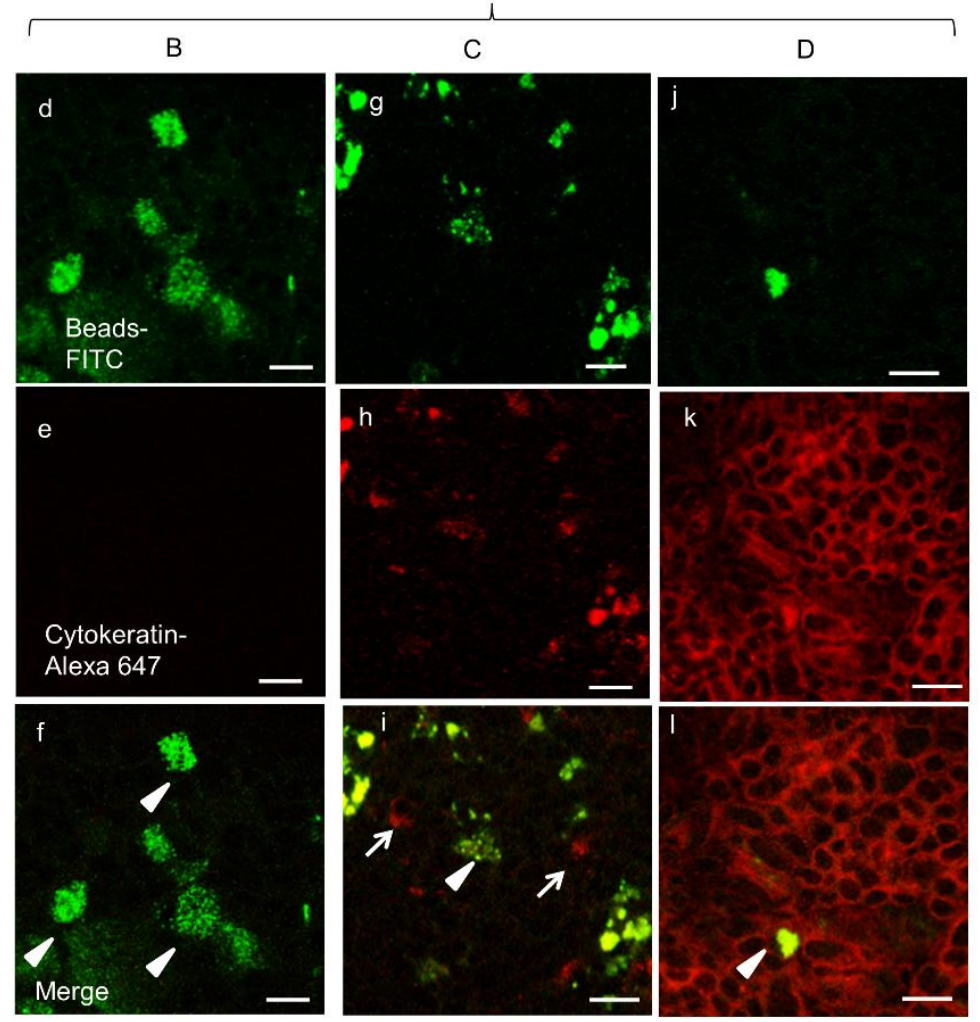


Fig.7
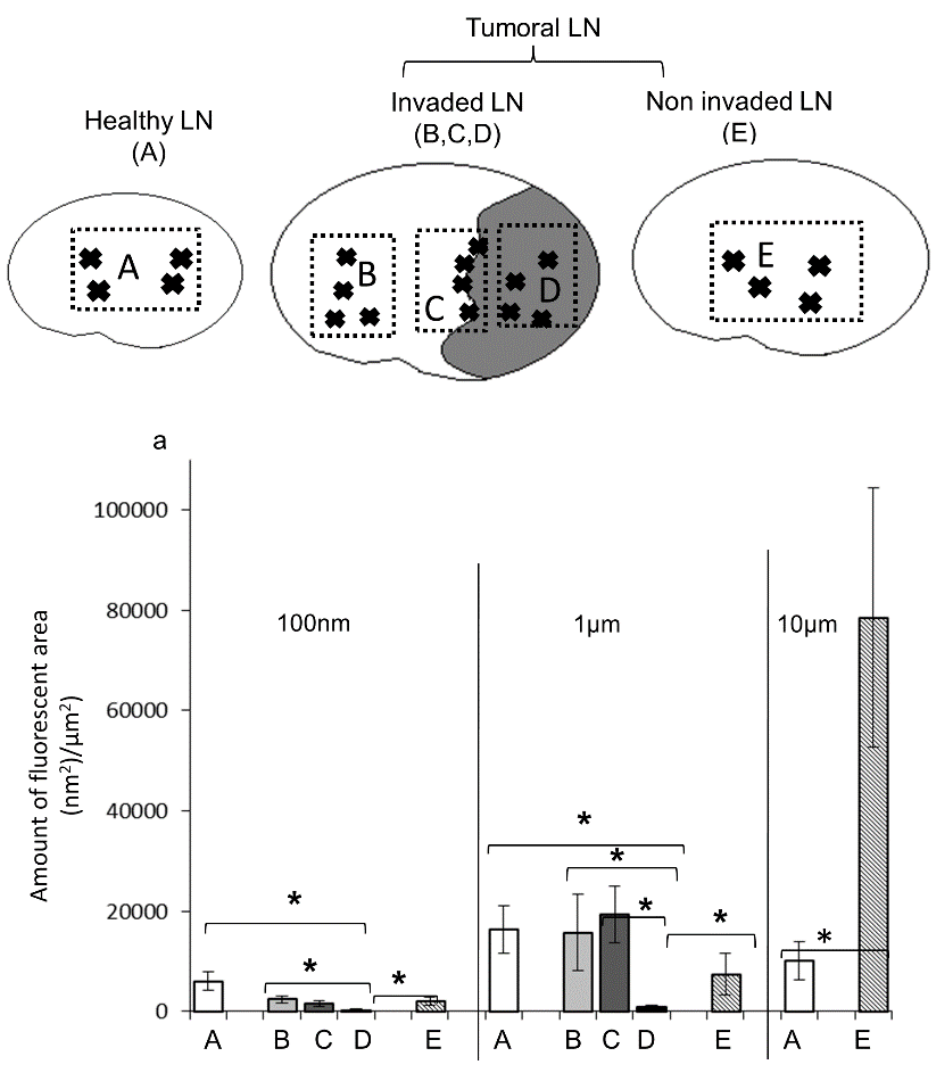